\title{
ACTIVATING LEARNERS IN FOREIGN LANGUAGE LESSONS
}

The article deals with the importance of activating methods that can be applied in the process of foreign language teaching and learning and are used to stimulate learners' interest in languages and to motivate them. If learners do things actively in lessons, if they discover language rules and vocabulary for themselves, they feel engaged and involved in the process and they can remember new structures and lexical units better and for a longer period of time. In the process of active learning teacher becomes a facilitator whose most important task is to facilitate learning by following cognitive, affective and linguistic principles, by creating a supportive atmosphere in the classroom and by exposing learners to as much language as possible not only at school but also at home.

\section{Introduction}

Stimulating learners' interest in a subject is one of the main preconditions of successful learning, and it is also of major importance when learning a foreign language. One could even claim that learners' motivation is the basis of foreign language learning. "The research on motivation defines motivation as an orientation towards a goal. (This orientation may be positive, negative, or ambivalent.) Motivation provides a source of energy that is responsible for why learners decide to make an effort, how long they are willing to sustain an activity, how hard they are going to pursue it, and how connected they feel to the activity.”([4], 2006, p. 1) Stimulating learners' interest and motivating learners to learn the subject are only possible if certain preconditions are met.

\section{The Importance of Active Learning}

If we want to engage learners in the learning process and motivate them, it is essential that they are given an opportunity to learn actively. If they just sit in lessons and listen to teachers explanations passively, one cannot be sure if the process of learning is really taking place and how much learners learn. If this happens in foreign language lessons, instead of learning the target language and using it as a means of communication, learners just listen to a talk about the language, which - of course - is different from the objectives of language teaching. Scrivener ([5], 2005, p. 17) states that there is an important formula: $\mathrm{T} \neq \mathrm{L}$, which means that teaching does not equal learning. In other words - teaching does not necessarily lead to learning. That is the reason why modern methodology emphasizes the meaning of those methods that make it possible for learners to learn actively. These methods stimulate learners, make them solve problems, answer question, formulate their own questions, discuss topics, argue, or explain their opinions.

When learning actively, learners are engaged in the process of learning. This way of learning is in contrast with "passive" learning when learners just listen to teacher's explanations and do whatever they are told to do. Learners who work with materials actively remember the subject matter much better; after a certain period of time they can recall more easily what they did than they can if they just listen to the teacher; and are also able to use the studied language structures and vocabulary in other contexts ([5], 2005, p. 18).

Active learning is often connected with co-operative learning in small groups which supports the collaboration between learners when solving various tasks and problems. In this way teacher knows whether learners really understand the subject matter because without understanding it they would not be able to solve the task or the problem independently. Their way of learning is particularly beneficial for low achievers who get the explanation from someone else and not teacher; and it is also good for high achievers who develop their skills by helping others. In a different situation learners can be divided according to their achievements and they can be allowed to choose activities that meet their needs.

Co-operative learning not only contributes to the development of learners' skills, but it also helps them gain their independence and autonomy. In addition to that, it helps them understand how to work in teams, how to become tolerant of the ideas of the other members of the team, or how to be respectful. In this way it not only contributes to their active learning, but it also prepares them for real life by giving them opportunities to acquire interpersonal skills they will definitely need in the future.

\section{The Role of Teacher}

Active approach towards learning means that the role of teacher in the classroom changes considerably. Teacher is not a controller any more and does not have the whole class under his/her control at every moment of the lesson, but $\mathrm{s} / \mathrm{he}$ becomes a facilitator whose main task it is to facilitate learning, which means s/he has to give learners enough space to 'experiment' with the language and to use

\footnotetext{
* Danica Gondová

Department of English Language and Literature, Faculty of Science of Žilina University, Žilina, Slovakia, E-mail: Danica.Gondova@fpv.utc.sk
} 
it actively. The facilitator makes it possible for learners to acquire practical experience of the language which they gain thanks to the fact that they can use it actively when doing various problem-solving tasks, projects, etc. Teacher manages the process of their learning, s/he supports them, helps them, or prompts them. However, $\mathrm{s} /$ he should not help too much because, actually, then s/he becomes an obstacle to the learning process. As a facilitator, teacher should know how learners learn and which learning styles they prefer so that $\mathrm{s} / \mathrm{he}$ can help learners in this direction. $\mathrm{S} /$ he should find out which materials or techniques help them learn more effectively. In the lessons, it is necessary to use various visual aids and kinaesthetic activities, and vary as many activities as possible so that learners have a chance to try out various learning styles. It is also necessary to support all intelligences of learners as they have been defined by Gardner (in [7], 2004, p. 13).

\section{Engaging Learners}

Learners are motivated if they can learn actively and if they can identify themselves with what is going on in the lesson. Therefore, a foreign language lesson should consist of activities during which learners do something actively and have to produce an outcome. Learners should do activities in pairs or in small groups, which has several advantages for them. In addition to the fact that it increases the time during which learners use the target language to communicate with each other and also to do the task, they also learn to be responsible for their learning and use the time they have at their disposal. Another advantage is that they learn from each other, which is motivating as well and contributes to gaining interpersonal skills.

Kolb's theory of experiential learning cycle ([6], 1996) has had an impact on teaching and learning foreign language as well and its principles are applied in foreign language methodology. Assuming that one is more engaged in what $\mathrm{s} / \mathrm{he}$ has to do or 'discover' himself/herself, grammar is no more explained in lessons and modern textbooks include many discovery techniques that force learners to think about the rules valid for the target language, to 'discover' their application and use. For this purpose, there are many presentation texts in textbooks that introduce new language structures, expose learners to the new language and help them understand how it functions in context. Like activities, discovery techniques also stimulate learners' interest, develop their thinking, teach them to be independent and responsible for their learning and, therefore, teacher should use them as much as possible. Using discovery techniques means that learners learn inductively. Inductive learning is more interesting for learners than deductive learning (based on explanations) and they remember what they have learned longer and better because they have found the solution themselves or in co-operation with their peers.

\section{Principles of Foreign Language Teaching/Learning}

Teaching/learning a foreign language has some other specific features that need to be respected by teachers if we really want to stimulate learners' interest in the subject. According to [2] (2002) teaching a foreign language has to follow some principles if it is to be successful. He divides the principles into three groups: cognitive, affective and linguistic. Even though they are all important for learners' motivation and active participation in the lesson, we would like to stress two of them:

The first one is the principle of meaningful learning instead of rote learning or memorizing grammar rules or vocabulary. Instead of teaching rules, teacher has to include activities that make it possible for learners to use language structures actively and instead of giving learners long lists of words to memorize they should do activities which allow them to 'interact' with words.

The second principle is that of interlanguage which [2] considers to be one of the affective principles. The interlanguage principle reflects the fact that learners have not mastered the target language yet and therefore make errors. Errors are considered to be a natural part of the learning process and learners should be given the right to learn from their own mistakes without being penalized or punished for them. It is teacher's responsibility to create a friendly and helpful atmosphere in the classroom in which learners feel the support of both teacher and their peers, and are willing to take risks and speak even though they know they make mistakes.

The above mentioned principles build up the trust of learners and develop and increase their self-confidence because they give them opportunities to experience success repeatedly. Experiencing success motivates learners to learn even more actively. A major role is also played by positive affective feedback that enables teacher to approach learners individually and appreciate their progress even if it is not great. It is teacher's responsibility to be respectful towards learners and evaluate not only their achievements, but also their effort. Learners should understand that teacher is their partner and respects and values them as they are.

\section{Other Preconditions of Active Learning}

Learners are also activated if they are allowed to make decisions about objectives, or activities they are going to do, and to contribute to the lesson. If teacher enables this, learners understand that what they are doing is important to them and can identify themselves with the objectives more easily than in situations in which everything is decided for them by someone else. It is necessary to teach learners that they have to set goals for themselves and that the goals need to be realistic and achievable within a relatively short period of time. Children are not able to realize how important it will be for them to master foreign languages when looking for a job in the future. Such an aim cannot stimulate or motivate them and therefore teacher should help them to work towards goals that are achievable within a short period of time and are manageable.

Another precondition of learners' motivation is enhancing the foreign language atmosphere in the classroom. This can be achieved by putting various posters or advertisements on the walls, as well as by teaching the lesson in the target language. Using simple 
instructions, body language and facial expressions it is possible to teach e.g. English through English even to complete beginners. Of course, it makes demands on teacher's preparations and plans because $\mathrm{s} /$ he has to think thoroughly not only about how to give instructions so that learners can understand them, but also about how to work with new vocabulary, language structures and other textbook or supplementary materials. We need to keep in mind that the organization of the lesson and managing learners are those moments when teacher really communicates with the learners and really tries to say something they need to understand and respond to it. (Activities and exercises are often done by learners just because teacher wants them to do so, not because they want to communicate.) This is the reason why we consider these parts of lessons very important and believe that they contribute to stimulating learners' interest in the target language.

It is also necessary to ensure that learners have sufficient input materials in the target language. They should have an opportunity to listen and read extensively. In addition to using all the listening materials that are part of the textbook, teachers can also use films, popular songs and they can encourage students to watch television programmes in the target language at home. As to reading materials, teachers should build up a library in which learners find books and magazines appropriate to their age and language level. An inexhaustible source of reading materials is the Internet. Not only those websites that are meant for learners, but also any other websites that learners can use according to their own interest quite early if they are helped by teacher.

Extensive reading and listening increase the learners' contact time with the target language due to which their achievements might improve. If learners are to make progress in the target language, they should have at least 4 lessons per week ([4], 2006). However, many students do not have such a number of lessons at their disposal and so - again - it is the responsibility of teacher to set homework that is stimulating and entertaining so that learners can enjoy working with foreign language materials. Teachers should use not only what the textbook offers, but they should also motivate learners to read and listen outside the classroom and set home assignments that make learners use the Internet and in this way practise vocabulary and language structures. Learners can also be asked to find some information on the Internet. If they manage to do that, they experience success, which motivates them to further work.

Another factor that increases learners' motivation is the personalization of various topics. Learners should have enough space to talk or write about themselves, their interests, families and later they should be encouraged to express their own opinions and points of view. They can carry out various investigations in their classes or at school; they can make a newspaper or a magazine, or create other materials. It is excellent if they have the impression that in foreign language lessons they talk about their own lives, interests and problems. At higher levels of language acquisition they can learn to understand value systems, develop critical thinking and discuss everyday issues or global problems.

In conclusion, we would like to stress that if we want to motivate learners to study foreign languages, it is necessary to choose methods that are learner-oriented, that take their needs and interests into consideration and make it possible for them to experience success. Affective principles play an essential role in this process because thanks to them learners can overcome their inhibitions and fears of talking in a foreign language that they do not master at the same level as their mother tongue. Affective principles also help create friendly and supportive atmosphere in the classroom which also stimulates learners' interest in the language and motivates them.

\section{References}

[1] Active/Cooperative Learning, Foundation Coalition, 16. december 2006 [cit. 2006-12-16] http://www.foundationcoalition.org/home/keycomponents/collaborative_learning.html

[2] BROWN, H. D.: Teaching by Principles, An Interactive Approach to Language Pedagogy, 2001

[3] HARMER, J.: The Practice of English Language Teaching, Longman 2004

[4] ROST, M.: Generating Student Motivation, WorldView, 2006, [cit. 2006-12-02] http://www.longman.com/ae/worldview/motivation.pdf

[5] SCRIVENER, J.: Learning Teaching, Macmillan, 2005

[6] SMITH, M. K.: 1996 David A. Kolb on Experiential Learning, The Encyclopaedia of Informal Education 2005-01-30, [cit. 2006-1203] http://www.infed.org/biblio/b-explrn.htm

[7] STRAKOVA, Z.: Introduction to Teaching English as a Foreign Language, Prešov, 2004. 